\title{
Aerosol quantification with the Aerodyne Aerosol Mass Spectrometer: detection limits and ionizer background effects
}

\author{
F. Drewnick ${ }^{1}$, S. S. Hings ${ }^{1}$, M. R. Alfarra ${ }^{2,}$, A. S. H. Prevot ${ }^{2}$, and S. Borrmann ${ }^{1,3}$ \\ ${ }^{1}$ Max Planck Institute for Chemistry, Particle Chemistry Department, Mainz, Germany \\ ${ }^{2}$ Paul Scherrer Institute, Laboratory of Atmospheric Chemistry, Villigen, Switzerland \\ ${ }^{3}$ Johannes Gutenberg University Mainz, Institute for Atmospheric Physics, Mainz, Germany \\ *now at: Centre for Atmospheric Sciences, University of Manchester, Manchester, UK
}

Received: 7 October 2008 - Published in Atmos. Meas. Tech. Discuss.: 31 October 2008

Revised: 28 January 2009 - Accepted: 28 January 2009 - Published: 12 February 2009

\begin{abstract}
Systematic laboratory experiments were performed to investigate quantification of various species with two versions of the Aerodyne Aerosol Mass Spectrometer, a Quadrupole Aerosol Mass Spectrometer (Q-AMS) and a compact Time-of-Flight Aerosol Mass Spectrometer (c-ToFAMS). Here we present a new method to continuously determine the detection limits of the AMS analyzers during regular measurements, yielding detection limit $(D L)$ information under various measurement conditions. Minimum detection limits range from $0.03 \mu \mathrm{g} \mathrm{m}^{-3}$ (nitrate, sulfate, and chloride) up to $0.5 \mu \mathrm{g} \mathrm{m}^{-3}$ (organics) for the Q-AMS. Those of the c-ToF-AMS are found between $0.003 \mu \mathrm{g} \mathrm{m}^{-3}$ (nitrate, sulfate) and $0.03 \mu \mathrm{g} \mathrm{m}^{-3}$ (ammonium, organics). The $D L$ values found for the c-ToF-AMS were $\sim 10$ times lower than those of the Q-AMS, mainly due to differences in ion duty cycle. Effects causing an increase of the detection limits include long-term instrument contamination, measurement of high aerosol mass concentrations and short-term instrument history. The self-cleaning processes which reduce the instrument background after measurement of large aerosol concentrations as well as the influences of increased instrument background on mass concentration measurements are discussed. Finally, improvement of detection limits by extension of averaging time intervals, selected or reduced ion monitoring, and variation of particle-to-background measurement ratio are investigated.
\end{abstract}

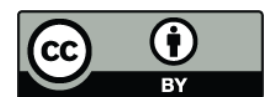

Correspondence to: F. Drewnick (drewnick@mpch-mainz.mpg.de)

\section{Introduction}

Aerosol Mass Spectrometry is a promising method to investigate the size and chemical composition of aerosol particles on-line and in real-time (Suess and Prather, 1999; Canagaratna et al., 2007). In recent years it was shown that the Aerodyne Aerosol Mass Spectrometers - the initial version, the Quadrupole Aerosol Mass Spetrometer (Q-AMS), as well as the recently developed Time-of-Flight Aerosol Mass Spectrometer (ToF-AMS) - have the capability of measuring aerosol properties like size distributions and chemical composition quantitatively and with high time resolution (e.g. Allan et al., 2003a; Drewnick et al., 2005; Hings et al., 2007). For quantitative instruments it is crucial to know their detection limits, i.e. the minimum detectable absolute amount for each substance under investigation and parameters possibly influencing these values. Until now, the detection limits of the Aerodyne AMS have only been determined for one special measurement condition via filter measurements during field campaigns or have been estimated from ion counting statistics. Allan et al. (2003a and b) were the first who estimated Q-AMS detection limits using ion counting statistics considerations; Bahreini et al. (2003a), Allan et al. (2003a), Zhang et al. (2005) and Salcedo et al. (2006) determined Q-AMS detection limits as three times the standard deviation of the mass recorded during measurements of filtered air during various field campaigns. Takegawa et al. (2005) also determined Q-AMS detection limits for nitrate, sulfate, ammonium and organics via filter measurements and compared them to the detection limits obtained using the procedures described in (Allan et al., 2003a and b). DeCarlo et al. (2006) compared detection limits of QAMS, c-ToF-AMS and HR-ToF-AMS extracted from filter measurements. However, no systematic investigation of the

Published by Copernicus Publications on behalf of the European Geosciences Union. 


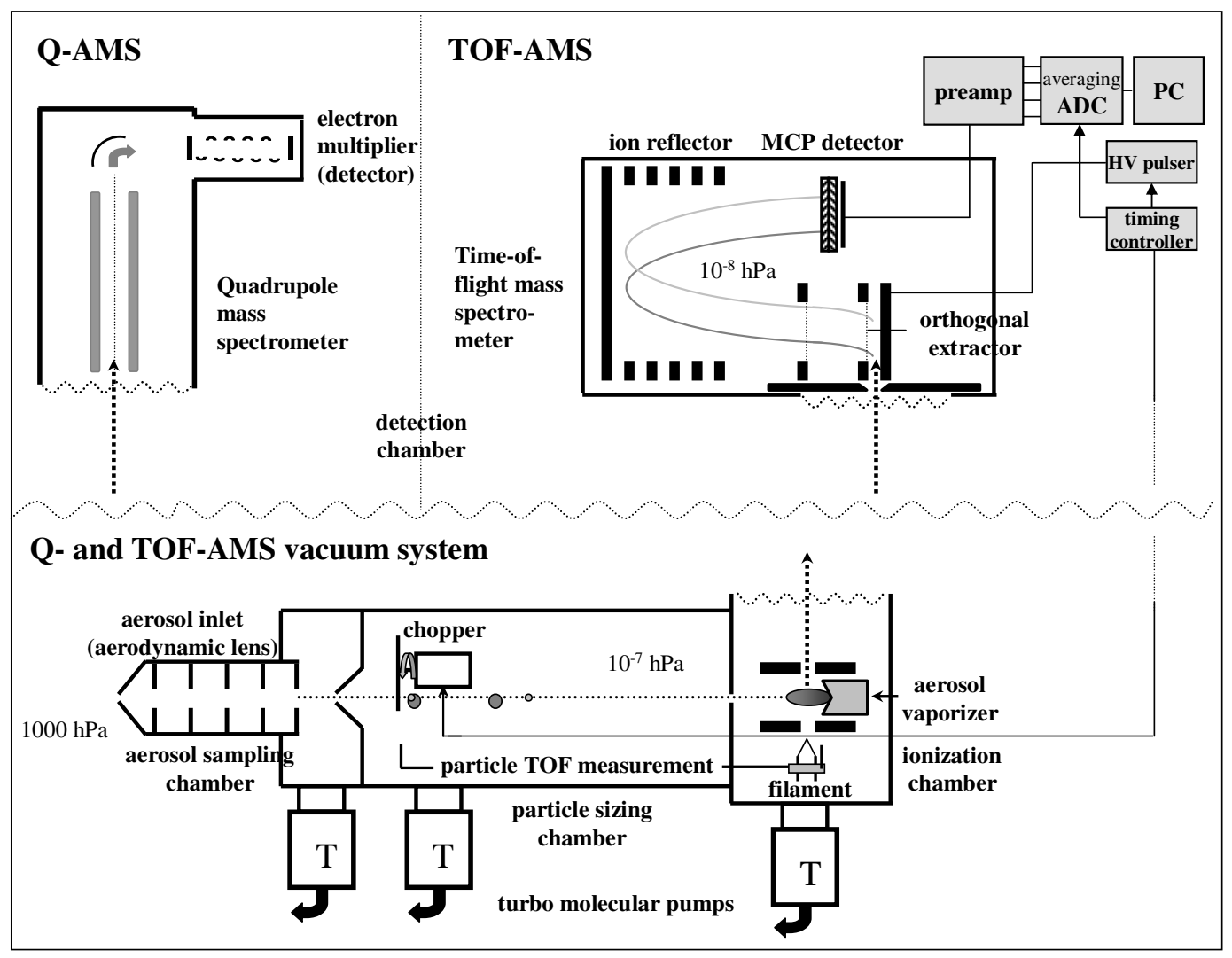

Fig. 1. Schematic diagrams of Q-AMS and ToF-AMS.

Q- and ToF-AMS detection limits, their dependency on measurement conditions and other factors, and approaches to reduce the detection limits have been reported so far.

In this paper we present a new method to determine AMS detection limits from regular aerosol measurements without the need to measure filtered air. This method for the first time provides the possibility to continuously determine detection limits and therefore to investigate the influence of the measurement conditions on these values. Systematic laboratory measurements of the detection limits $(D L)$ of the analyzers (i.e. the whole analytical system in the AMS from the particle vaporizer to the detector) of both a Q- and a cToF-AMS are presented for a broad variety of measurement conditions. Not only the minimum detection limits of nitrate, sulfate, ammonium, chloride and organics were determined during measurements of filtered air, but also effects that increase the detection limits were investigated. These effects include the measurement of high concentrations of aerosol species, long-term instrument contamination (time scale: days to weeks) as well as short-term instrument history (time scale: up to tens of seconds). Here especially the self-cleaning processes of the instrument and the influence of increased background concentrations on mass concentration measurements are discussed in detail. Measured detection limits are compared to detection limits determined by ion counting statistics considerations $\left(D L_{\text {stat }}\right)$ similar to the procedure described by (Allan et al., 2003a and b). Finally, approaches to improve the instruments' detection limits were investigated and discussed. These include extension of averaging times, changes of aerosol-to-background measurement time ratio, and the reduction of number of $\mathrm{m} / \mathrm{z}$ that are used for mass concentration calculations.

\section{Experimental}

\subsection{AMS instrument description}

A detailed description of the Q-AMS is given in (Jayne et al., 2000; Jimenez et al., 2003), and of the c-ToF-AMS in (Drewnick et al., 2005). Here only a brief description of the two instruments will be given. Both instruments (Fig. 1) have an identical vacuum system with an aerosol sampling chamber, a particle sizing chamber, a particle evaporation and ionization chamber, and a detection chamber, however their ion analysis technique is different: the Q-AMS uses a Balzers (now: Pfeiffer) quadrupole mass spectrometer (QMG 422), whereas the ToF-AMS uses a compact Tofwerk orthogonal extraction time-of-flight mass spectrometer (TOFMS, e.g. Steiner et al., 2001). In this manuscript we use "Q-AMS" 
and "ToF-AMS" always when we want to denote specifically one of these instrument types. If the statements are true for both types of Aerodyne AMS we use the acronym "AMS".

The aerosol is introduced into the AMS through a critical orifice $(100 \mu \mathrm{m}$ and $130 \mu \mathrm{m}$ diameter in the ToF-AMS and the Q-AMS used in this study, respectively) and an aerodynamic lens assembly (Zhang et al., 2002; Zhang et al., 2004). The critical orifice limits the inlet flow into the instrument to a nominal flow rate of $1.4 \mathrm{~cm}^{3} \mathrm{~s}^{-1}$ (ToF-AMS) and $2.0 \mathrm{~cm}^{3} \mathrm{~s}^{-1}$ (Q-AMS). The aerodynamic lens focuses aerosol particles in the size range $50-600 \mathrm{~nm}$ with an efficiency of almost $100 \%$ into a narrow beam. Below and above this size range the transmission efficiency of the inlet system decreases and reaches negligible values below $30 \mathrm{~nm}$ and above approximately $1.5 \mu \mathrm{m}$. After passing the sampling chamber, the aerosol is directed through a skimmer into the particle sizing chamber, while most of the surrounding gas is pumped away. At the front end of the particle sizing chamber the particle beam can be modulated by a mechanical chopper for particle size measurements (not discussed here) or completely blocked for instrument background measurements.

After passing another aperture the particle beam travels through the evaporation and ionization chamber, where it impacts onto the vaporizer, a conical porous tungsten surface typically heated up to a temperature in the order of $600^{\circ} \mathrm{C}$. Upon impaction onto this surface the non-refractory aerosol components flash-vaporize and the resulting vapor molecules are ionized by electron impact $(E=70 \mathrm{eV})$. The positive ions are guided into the detection chamber which contains the mass spectrometer.

In the Q-AMS the ions are continuously guided into the quadrupole mass spectrometer which selects ions according to their mass-to-charge ratio $(\mathrm{m} / \mathrm{z})$ before their detection by a calibrated electron multiplier. In the ToF-AMS the ions are transferred into the extractor of the time-of-flight mass spectrometer and accelerated orthogonally to their flight direction into the flight tube of the mass spectrometer by a pulsed electrical field (pulsing frequency $\sim 83.3 \mathrm{kHz}$ ).

2.2 Instrument operation and calculation of aerosol mass concentrations

In order to measure mass concentrations for non-refractory aerosol components the aerosol beam is alternately either permitted to quantitatively pass the chopper (beam open) or completely blocked by the chopper (beam blocked). In the beam open position of the chopper, mass spectra of the nonrefractory aerosol components for an ensemble of particles are recorded together with a fraction of the air surrounding the particles and with the instrument background, while measuring with the beam blocked gives the background signal due to residual air and vapor molecules in the ionization chamber only. By subtracting it from the mass spectrum measured in the beam open position, one obtains the mass spectrum of the non-refractory aerosol components with a signal from the surrounding air (Airbeam) only. In the QAMS a complete mass spectrum is typically scanned over a mass range of $\mathrm{m} / \mathrm{z} 1-300$ within $300 \mathrm{~ms}$, with only one $\mathrm{m} / \mathrm{z}$ being detected at any given time, while in the ToF-AMS a whole mass spectrum is typically acquired every $12 \mu \mathrm{s}$ with every extraction pulse of the orthogonal extractor.

For the conversion of the measured AMS mass spectra into mass concentrations of various species first the signal intensity corresponding to every single $\mathrm{m} / \mathrm{z}$ in the spectrum (i.e. the unit resolution spectrum) is derived from the raw mass spectrum. This procedure involves determination of the average signal intensity in the center of the peak (Q-AMS, Allan et al., 2003b) or integration of the total peak area (ToFAMS, Drewnick et al., 2005). The vaporization and $70 \mathrm{eV}$ electron impact ionization of a certain chemical species in the AMS leads to a specific number of $m / z$ peaks in the mass spectrum, with a characteristic fragmentation pattern for that species. The sum of all signal intensities at all $\mathrm{m} / \mathrm{z}$ that correspond to a specific species gives the total species signal intensity $I_{s}$. Application of the algorithm described in (Allan et al., 2004) corrects for the fact that some $m / z$ contain interfering signals from several species in the calculation of species mass concentrations. This is identical for both, Q-AMS and ToF-AMS, since the fragmentation of the various species is only a result of the vaporization and $70 \mathrm{eV}$ ionization process. The mass concentration $C_{s}$ of a chemical species $s$ (in $\mu \mathrm{g}$ of particulate mass per $\mathrm{m}^{3}$ of air) can be calculated from the species signal intensities after Eq. (6) from Jimenez et al. (2003a), including the species collection efficiency $C E_{s}$ :

$C_{s}=\frac{1}{C E_{s} \cdot R I E_{s}} \cdot \frac{\sum_{f} I_{s f}}{N_{A} Q} \cdot \frac{M W_{\mathrm{NO}_{3}}}{I E_{\mathrm{NO}_{3}}}$

with $\sum_{f} I_{s f}$ the total signal intensity of species $s$ summed over all fragments $f, M W_{\mathrm{NO}_{3}}$ the molecular weight of nitrate $\left(62 \mathrm{~g} \mathrm{~mol}^{-1}\right), I E_{\mathrm{NO}_{3}}$ the calibrated ionization and transmission efficiency of nitrate, $N_{A}$ Avogadro's number, $Q$ the volumetric aerosol flow rate into the instrument, and $R I E_{S}$ the relative ionization efficiency of species $s$, a factor which corrects for differences in the ionization efficiencies $(I E)$ of different species with respect to the calibrated $I E_{\mathrm{NO}_{3}}$.

\subsection{The general concept of limits of detection and its appli- cation to AMS measurements}

For a reliable chemical analysis at trace levels it is important to know the smallest concentration or amount of analyte that can be detected by the analyzer. The problem in general is to differentiate between responses given by a blank and by a sample with a low concentration of the analyte, or in other words, detecting a weak signal in the presence of background signal and noise. Measurements are subject to random errors, which typically produce a normal distributed error curve. Therefore the distributions of replicate blank and sample measurements will overlap as the two average signals approach each other in magnitude, and at some point the 
chance of mistakenly identifying the analyte as present when it is not or vice versa reaches an unacceptable level. For this reason, the detection limit $(D L)$ must be defined in statistical terms and is defined as the measured concentration that can be distinguished from the blank signal with a certain statistical confidence. By convention (e.g. Kellner et al., 2004), it is defined as

$D L=\mu_{b}+3 \cdot \sigma_{b}$

with $\mu_{b}$ the arithmetic mean and $\sigma_{b}$ the standard deviation of a set of blank measurements. For this definition it is assumed that the measurement of the analyte concentration at $D L$ level is sufficiently close to the measurement at zero concentration (blank), so that the error curves of both measurements are sufficiently well described by the standard deviation of the blank measurements $\sigma_{b}$. With the center points of both distributions being three standard deviations apart from each other the probability for a wrong decision (in either way) is only $0.3 \%$ (under the Gaussian assumption).

For the AMS the detection limit $D L_{\text {Filter }}$ was defined in earlier publications as three times the standard deviation $\sigma_{\text {Filter }}$ of the measured mass concentration when a particle filter was placed in front of the instrument inlet (e.g. Bahreini et al., 2003; Takegawa et al., 2005; Zhang et al., 2005; Salcedo et al., 2006; and DeCarlo et al., 2006):

$D L_{\text {Filter }}=3 \cdot \sigma_{\text {Filter }}$

While such blank measurements with the AMS provide reliable information on the instruments detection limits, they possess significant disadvantages and limitations. The major disadvantage of this method is the fact that such a blank measurement needs the collection of filtered air for typically several tens of minutes, resulting in loss of ambient aerosol data for this time interval. While during week or month-long measurement campaigns such interruptions might be acceptable, such interruptions of regular measurements are typically not acceptable in situations where measurement time is very precious like during aircraft campaigns.

In addition to loss of measurement time the measurements of filtered air over extended time intervals to determine instrument detection limits have a major limitation: they provide $D L$ values only for a certain time interval and for special measurement conditions. Since the detection limits generally depend on the instrument background they will change over time as the background of the instrument changes. For example after a fresh pump-down of the instrument the instrument background - and consequently the detection limits - will decrease over time. During aircraft measurements, when the pumping of the instrument was started just before the flight this will result in decreasing $D L$ values over the time of the measurement. $D L$ measurements after the flight will in this case not only cost precious measurement time, but also provide detection limits that are lower than those actually valid during the flight. In addition to this inadequate representation of the actual detection limits by filter measurements this standard method is not capable of providing information on the influence of constant or rapidly changing influences of measured aerosol concentrations on the detection limits of the various species as investigated in the present work.

In order to overcome both the disadvantage and the limitations of filter measurement-based determination of detection limits we developed a new method to continuously determine the AMS detection limits without the need to interrupt the regular measurements and in agreement with the standard definition of detection limits.

As described above, for each single aerosol beam measurement also the background signal $I_{b}$ is determined during regular AMS measurements. The aerosol concentrations are extracted from the difference of multiple aerosol beam measurements and background measurements, performed during the same averaging interval. For mass concentration measurements near the detection limit the measured signal levels of the aerosol beam measurement and the instrument background measurement will be very similar to each other, resulting in very similar noise levels. Therefore, the $D L$ of mass concentrations obtained from the AMS can be experimentally determined from the instrument background signal during regular aerosol measurements from a set of consecutive measurements under identical conditions and is given by

$D L_{\mathrm{AMS}}=3 \cdot \sqrt{2} \cdot \sigma\left(I_{b}\right)$

with $\sigma\left(I_{b}\right)$ the standard deviation of the background signal $I_{b}$. The sqrt(2) in Formula 4 is used to convert the noise level of the background measurement into the noise level that would be obtained when calculating the difference signal of two signals with similar intensity as the background signal. These $D L$ will be used here to experimentally determine AMS detection limits for individual species under various measurement conditions. Note, that this definition of detection limits provides a lower limit for the $D L$ values since gas phase interferences to several $\mathrm{m} / \mathrm{z}$ during the aerosol measurements, causing increased noise levels are not considered here. In addition the quantification uncertainties due to particle counting statistics are not addressed in this approach. A discussion of averaging time limitations imposed by particle counting statistics is provided in Bahreini et al. (2003) and DeCarlo et al. (2006).

There are various contributions to the observed variations in the background signal. Limited ion counting statistics due to the small number of ions reaching the detector per unit time at the individual $\mathrm{m} / \mathrm{z}$ is one of the major contributions. Additional variation is produced by the distribution of detector signal intensities, generated by individual ions reaching the detector. Further factors are real fluctuations in background species concentration, ionization electron flux variations or electronic noise. While the experimental determination of the $D L$ according to Eq. (4) accounts for all these contributions, an estimate of $D L$ levels can be obtained by an approach introduced by (Allan et al., 2003a and b) that 
Table 1. Limits of Detection and uncertainties ( $1 \sigma)$ of Q-AMS and ToF-AMS, derived from filter measurements ( $30 \mathrm{~s}$ averaging time). $D L$ are experimentally determined using the new continuous method, $D L_{\text {Filter }}$ are experimentally determined using the standard method, and $D L_{\text {stat }}$ are estimated from ion counting statistics. In all cases, the detection limits are calculated for $30 \mathrm{~s}$ averaging intervals.

\begin{tabular}{lcccccc}
\hline & \multicolumn{2}{c}{$D L, \mathrm{ng} \mathrm{m}^{-3}$} & \multicolumn{2}{c}{$D L_{\text {Filter }}, \mathrm{ng} \mathrm{m}^{-3}$} & \multicolumn{2}{c}{$D L_{\text {stat }}, \mathrm{ng} \mathrm{m}^{-3}$} \\
\hline Species & Q-AMS & ToF-AMS & Q-AMS & ToF-AMS & Q-AMS & ToF-AMS \\
\hline Nitrate & $20 \pm 4$ & $3 \pm 0.3$ & $30 \pm 4$ & $5 \pm 0.7$ & 20 & 5.6 \\
Sulfate & $30 \pm 4$ & $3 \pm 0.3$ & $30 \pm 8$ & $4 \pm 0.4$ & 20 & 14 \\
Ammonium & $140 \pm 20$ & $30 \pm 6$ & $200 \pm 40$ & $40 \pm 6$ & 100 & 60 \\
Chloride & $30 \pm 3$ & $20 \pm 2$ & $30 \pm 7$ & $20 \pm 2$ & 40 & 20 \\
Organics & $440 \pm 50$ & $25 \pm 6$ & $500 \pm 70$ & $20 \pm 3$ & 200 & 30 \\
\hline
\end{tabular}

only accounts for ion counting statistics and single ion signal intensity distribution. The distribution of the number of detected ions at an individual $\mathrm{m} / \mathrm{z}$ can be described by a Poisson distribution. To account for the influence of the single ion signal distribution the width of the Poisson distribution is multiplied by a factor of $\alpha=1.2$, which was determined from single-ion measurements with the Q-AMS (Allan et al., 2003b). In accordance with the standard definition of the $D L$ (Eq. 2) and with our approach to continuously determine $D L$ values (Eq. 3) we define the detection limit $D L_{\text {stat }}$ (given in ions per second) determined from this approach as:

$D L_{\mathrm{stat}}=3 \cdot \sqrt{2} \cdot \Delta I_{b}=3 \cdot \sqrt{2} \cdot \alpha \cdot \frac{\sqrt{I_{b}}}{\sqrt{t_{s}}}$

with $I_{b}$ the background (beam closed) signal in ions $\mathrm{s}^{-1}$, and $t_{s}$ the total time in seconds spent sampling the particular $\mathrm{m} / \mathrm{z}$ channels associated with this signal. For each individual $\mathrm{m} / z$ in the Q-AMS $t_{s}$ is equal to the time spent measuring the background signal, divided by the total number of $\mathrm{m} / \mathrm{z}$ scanned (typically 300) and multiplied by the fraction of the peak area used to determine signal intensity (0.4); for the ToF-AMS $t_{s}$ is equal to the time spent measuring the background signal in MS mode times the duty cycle of ion extraction of the TOF-MS (Drewnick et al., 2005). The $D L_{\text {stat }}$ obtained from Eq. (4) are given in ions $\mathrm{s}^{-1}$. They are converted into mass concentrations in the same way as the signal intensities of the raw spectra (Eq. 1). This detection limit is similar to the one defined by (Allan et al., 2003a and b).

In order to determine AMS detection limits under various measurement conditions three types of measurements were performed with both instruments: Measurements of filtered air ( $2 \mathrm{~h}, 30 \mathrm{~s}$ averaging); measurements at various constant aerosol mass concentrations $\left(0.3,7,20\right.$, and $80 \mu \mathrm{g} \mathrm{m}^{-3}$ nitrate, 4,20 , and $50 \mu \mathrm{g} \mathrm{m}^{-3}$ sulfate; $1 \mathrm{~h}, 30 \mathrm{~s}$ averaging); and measurements of filtered air directly after the measurement of high aerosol concentrations (90 and $150 \mu \mathrm{g} \mathrm{m}^{-3}$ nitrate, $100 \mu \mathrm{g} \mathrm{m}^{-3}$ sulfate, and $200 \mu \mathrm{g} \mathrm{m}^{-3}$ organics). The aerosol was generated using a Constant Output Atomizer (TSI, Model 3076) and a diffusion dryer (TSI, Model 3062) filled with silica gel. For generation of nitrate aerosol a solution of ammonium nitrate was used, for the sulfate aerosol ammonium sulfate solution was nebulized. The particle size distribution generated by the atomizer was located in the 100-300 nm range after drying - in the center of the AMS sampling size range. A CPC (TSI, Model 3025) was used to monitor the temporal stability of the aerosol concentration.

\section{Results and discussion}

\subsection{Minimum AMS detection limits}

During measurements of filtered air the AMS instrument background and its variations reach their minimum levels. Therefore the detection limits measured during these experiments are the lowest possible detection limits that can be achieved with the AMS in the present configuration for the applied operation parameters under regular operation conditions, assuming no long-term contaminations have caused increased $D L$ values.

Filtered air was measured with both types of AMS over two hours with averaging intervals of $30 \mathrm{~s}$. The data from the last $30 \mathrm{~min}$ was used to extract the detection limits for the individual species, shown in Table 1. The detection limits of the Q-AMS determined from the instrument background measurements using the new method (Eq. 4) range from 20$30 \mathrm{ng} \mathrm{m}^{-3}$ (nitrate, sulfate, and chloride) up to $440 \mathrm{ng} \mathrm{m}^{-3}$ (organics, all signals not associated with any of the other species or air). Those of the ToF-AMS are found to be between $3 \mathrm{ng} \mathrm{m}^{-3}$ (nitrate, sulfate) and $30 \mathrm{ng} \mathrm{m}^{-3}$ (ammonium, organics). The relative uncertainties ( $1 \sigma$ of calculated $D L)$ are in the order of $10-20 \%$ of the measured values. Generally the lowest detection limits were found for those species that produce only few fragments with good signalto-noise ratios. Species that have fragments at $m / z$ with high background contributions from other species (like ammonium with high water- and air-related background signals) or species that have contributions at a very large number of $\mathrm{m} / \mathrm{z}$, each with small signal-to-noise ratio (like organics with 
Table 2. Comparison of detection limits determined for the Q-AMS and ToF-AMS within this study and in the literature; all values are provided in $\mathrm{ng} \mathrm{m}^{-3}$. The first value is for the Q-AMS, the second value for the ToF-AMS. All values are scaled to $t_{s}=0.5 \mathrm{~min}$ averaging time assuming a proportionality of the detection limit with $1 / \operatorname{sqrt}\left(t_{s}\right)$.

\begin{tabular}{lcccccc}
\hline Citation & $t_{S}$ (original) & Nitrate & Sulfate & Ammonium & Chloride & Organics \\
\hline Allan et al. (2003b) & $15 \mathrm{~min}$ & $33 /-$ & $82 /-$ & $-/-$ & $-/-$ & $225 /-$ \\
Bahreini et al. (2003) & $1 \mathrm{~min}$ & $4330 /-$ & $3370 /-$ & $6130 /-$ & $-/-$ & $16580 /-$ \\
Takegawa et al. (2005) & $1 \mathrm{~h}$ & $220 /-$ & $110 /-$ & $2200 /-$ & $220 /-$ & $3300 /-$ \\
Zhang et al. (2005) & $10 \mathrm{~min}$ & $45 /-$ & $225 /-$ & $490 /-$ & $45 /-$ & $670 /-$ \\
Salcedo et al. (2005) & $10 \mathrm{~min}$ & $45 /-$ & $400 /-$ & $490 /-$ & $180 /-$ & $1800 /-$ \\
DeCarlo et al. (2006) & $1 \mathrm{~min}$ & $45 / 1.7$ & $225 / 3.1$ & $495 / 23$ & $45 / 5.6$ & $660 / 27$ \\
This study & $0.5 \mathrm{~min}$ & $20 / 3$ & $30 / 3$ & $140 / 30$ & $30 / 20$ & $440 / 25$ \\
\hline
\end{tabular}

more than 200 different $\mathrm{m} / \mathrm{z}$ signals contributing to the total signal), typically have high detection limits. An exception from this general behavior is the $D L$ measured for ToF-AMS chloride $\left(20 \mathrm{ng} \mathrm{m}^{-3}\right)$ which generates only four fragments at $\mathrm{m} / \mathrm{z}$, that are typically not affected by large background values. However, a detailed investigation of this effect has shown that the chloride-related $\mathrm{m} / \mathrm{z}$ are affected by a large and slowly decreasing background signal, a long-term contamination likely generated by maintenance work on the ionizer of this instrument approximately one week before the measurements. A broader discussion of such effects will be given below.

An overview over AMS detection limits provided in the literature and from this study is given in Table 2. Generally the same relative levels of detection limits are found for the individual species with low values for nitrate, sulfate and chloride and high $D L$ values for ammonium and organics. However, the absolute levels of the detection limits vary significantly between the individual measurements. For the ToF-AMS only $D L$ measurements by DeCarlo et al. (2006) exist in the literature, which (with the exception of chloride, see above) agree well with those measured in this study. For the Q-AMS similar detection limits to our values are found by Allan et al. (2003b) and DeCarlo et al. (2006). Larger values were reported by Zhang et al. (2005) and Salcedo et al. (2005) who both measured their detection limits during field campaigns in urban environments, where increased instrument contamination is expected. Much larger detection limit values than in our measurements were found by Bahreini et al. (2003) and Takegawa et al. (2005). Bahreini et al. (2003) determined their detection limits during an aircraft campaign, where typically pumping times before the measurements are very short, resulting in large instrument background values. Takegawa et al. (2005) determined their detection limits for 1-h averaging intervals. These long measurement times could have resulted in increased values due to long-term instrument variations, which were further enhanced by scaling the $D L$ values to $0.5 \mathrm{~min}$ averaging times.
The same data set was used to calculate the instruments detection limits $D L_{\text {Filter }}$ using the standard method and Eq. (3), where the mass concentration is extracted from the difference of the aerosol beam and the instrument background signals during measurements through the filter. As shown in Table 1 the $D L_{\text {Filter }}$ agree well with those obtained with the continuous method that uses only the instrument background measurement to determine the instruments detection limits during regular measurements.

The observed differences between the measured ToF-AMS and Q-AMS $D L$ can largely be explained by the different ion transmission duty cycles of the two mass spectrometers, i.e. the fraction of the measuring time spent measuring a single $\mathrm{m} / \mathrm{z}$, as already mentioned by DeCarlo et al. (2006). In the Q-AMS the complete mass spectrum $(300 \mathrm{~m} / \mathrm{z})$ is scanned by the quadrupole mass spectrometer, using only 0.4 mass units per $\mathrm{m} / \mathrm{z}$ for ion signal determination. The duty cycle of the chopper is $50 \%$ (note that due to dead time after chopper movements the actual chopper duty cycle is slightly below this value, depending on the frequency of the chopper movements). The Q-AMS ion transmission duty cycle is therefore given by

$$
D_{\mathrm{Q}-\mathrm{AMS}}=\frac{0.4}{300} \cdot 50 \%=0.067 \%
$$

The duty cycle of the ToF-MS is limited by the effect of overfilling of ions in the orthogonal extractor (Fig. 1). This means that ions are lost during the analysis because they cross the whole extractor before they are injected into the TOF-MS. For the largest $\mathrm{m} / \mathrm{z}$ measured in the spectra (typically $m / z 300$ ) the related duty cycle is determined by the instrument geometry and $D_{\text {overfill }}=57 \%$. Since the velocity in the extractor is proportional to $\operatorname{sqrt}(\mathrm{m} / z)$ the resulting duty cycle for $m / z 28$ is $17.4 \%$. For this $m / z$, the total ion duty cycle, including the chopper duty cycle, is

$$
D_{\mathrm{TOF}-\mathrm{AMS}}=50 \% \cdot D_{\text {overfill }}=8.7 \%
$$

Because the $D L$ is inversely proportional to the square root of the sample time $t_{s}$ of a $\mathrm{m} / \mathrm{z}$ and therefore inversely proportional to the square root of the duty cycle of a $\mathrm{m} / \mathrm{z}$, the 
130 times larger ion duty cycle of the ToF-AMS converts into $\sim 11$ times lower detection limits, compared to the QAMS. This difference is smaller for species which fragment into $m / z<28$ (because of the reduced ToF-AMS duty cycle) and larger for species which fragment into $m / z>28$ (because of the higher duty cycle of the ToF-AMS and the contribution by electronic noise in the Q-AMS). If one accounts for the larger inlet flow into the Q-AMS used for these measurements $\left(2.0 \mathrm{~cm}^{3} \mathrm{~s}^{-1}\right)$, compared to the ToFAMS $\left(1.4 \mathrm{~cm}^{3} \mathrm{~s}^{-1}\right)$ the expected $D L$ of the Q-AMS are 9 times larger than those for the ToF-AMS, exactly the factor that was observed in the measured $D L$ of the two instruments. Therefore the observed differences in detection limits between the Q- and the ToF-AMS can be largely explained by differences in ion duty cycle of the two mass spectrometers.

As mentioned before, an estimate of $D L$ levels can also be obtained by accounting for variations in the measured background signal that are caused by counting statistics and single ion signal intensity distribution only. The $D L_{\text {stat }}$ presented in Table 1 have been calculated using this approach (Eq. 5). Generally the $D L_{\text {stat }}$ agree well with the measured $D L$ or are slightly lower. This is expected since they do not account for contributions like electronic noise or instrument background variations. Especially for organics where a large number of $\mathrm{m} / \mathrm{z}$ signals contribute significant electronic noise to the total signal of the Q-AMS a large absolute difference is found in the two values. In summary the $D L_{\text {stat }}$ is considered as a good estimate of instrument detection limit as long as counting statistics is the major contribution to background variation. However, this is not necessarily the case for Q-AMS organics (large contribution of electronic noise) or for species with $m / z$ fragments that are influenced by contributions from other species (cross-sensitivity, see below).

"Mass spectra" of detection limits have been generated by calculation of $D L$ values for each individual $\mathrm{m} / \mathrm{z}$ (Fig. 2) using the continuous method (Eq. 4). As expected the ToFAMS $D L$ are generally much lower than the Q-AMS $D L$. While the ToF-AMS $D L$ decrease with increasing $\mathrm{m} / z$, those of the Q-AMS stay more or less constant (except for the peaks with high background intensity). This difference has two main reasons: The ToF-AMS duty cycle increases with increasing $\mathrm{m} / \mathrm{z}$, causing better $S / N$ ratios; in addition, the ToF-AMS effectively reduces electronic noise by rejecting all signals below a certain threshold (Hings et al., 2007). This is not the case for the Q-AMS where electronic noise dominates more and more the signal found at high $\mathrm{m} / \mathrm{z}$. The highest $D L$ values for both instruments are found at $\mathrm{m} / \mathrm{z}$ with typically high background signal intensities, resulting in larger background variations. Those are fragments for example from water (e.g. $m / z 16,17,18$ ), air (e.g. $m / z 28,32$, $40,44)$ and potassium $(\mathrm{m} / \mathrm{z} 39$ and 41$)$. The high $D L$ values at $m / z, 182,183,184$ and 186 can be attributed to tungsten which is constantly emitted from the filament and always contributes to the background signal. For measure-
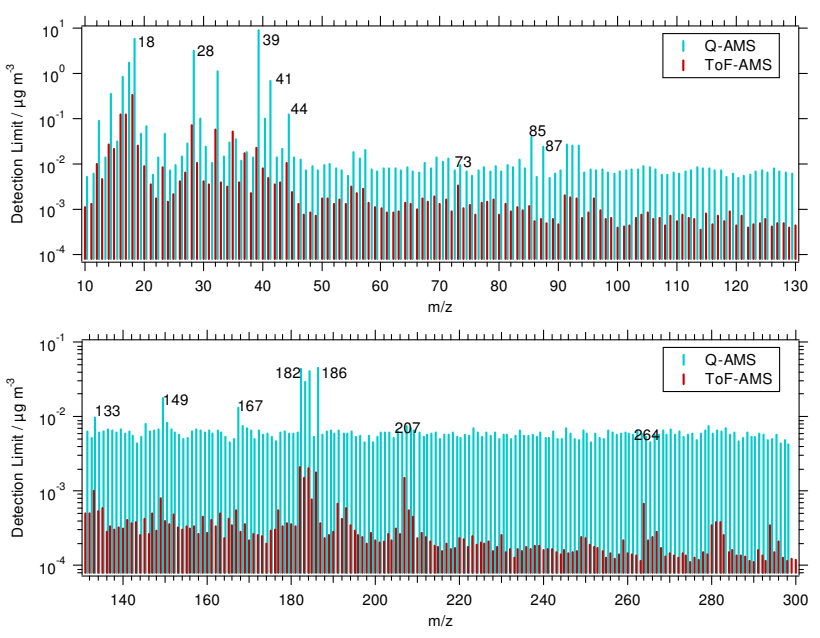

Fig. 2. Detection limits of individual $\mathrm{m} / \mathrm{z}$, experimentally determined from 30 seconds blank measurements for Q-AMS (blue) and ToF-AMS (red). The $m / z$ with the highest detection limits are labeled. Note, that the detection limits for the different species (as given in Table 1) are calculated from the noise of that species and are not simply the sum of the $D L$ of the corresponding $\mathrm{m} / \mathrm{z}$.

ments where these $\mathrm{m} / \mathrm{z}$ are of special interest filaments not containing tungsten could be used in order to improve the detection limits in this part of the mass spectrum. Species that have fragments at such $\mathrm{m} / \mathrm{z}$ with high $D L$ values will also have large detection limits.

\subsection{Ionizer background effects}

During real aerosol measurements the actual detection limits of the individual species can attain higher values than those presented in Table 1. This always happens when the background concentrations of individual $\mathrm{m} / \mathrm{z}$ signals are increased. Here we discuss three effects causing such increases: measurement of elevated aerosol mass concentrations, short-term instrument history, and long-term instrument contamination.

\subsubsection{Measurement of elevated mass concentrations}

When aerosol is measured most of the generated vapor molecules are not ionized and used for the mass spectrometric analysis. These residual molecules spread over the volume of the ionization chamber and are part of the instrument background until they are pumped away. Measurements of four and five different constant concentrations (range: 0 $100 \mu \mathrm{g} / \mathrm{m}^{3}$ ) of ammonium nitrate and ammonium sulfate, respectively were used to investigate the influence of aerosol measurements on the species' detection limits. The results of these measurements are summarized in Fig. 3 for the measurements of ammonium nitrate aerosol in the top panels and for the measurements of ammonium sulfate aerosol in the lower panels. In addition to the absolute increase of 


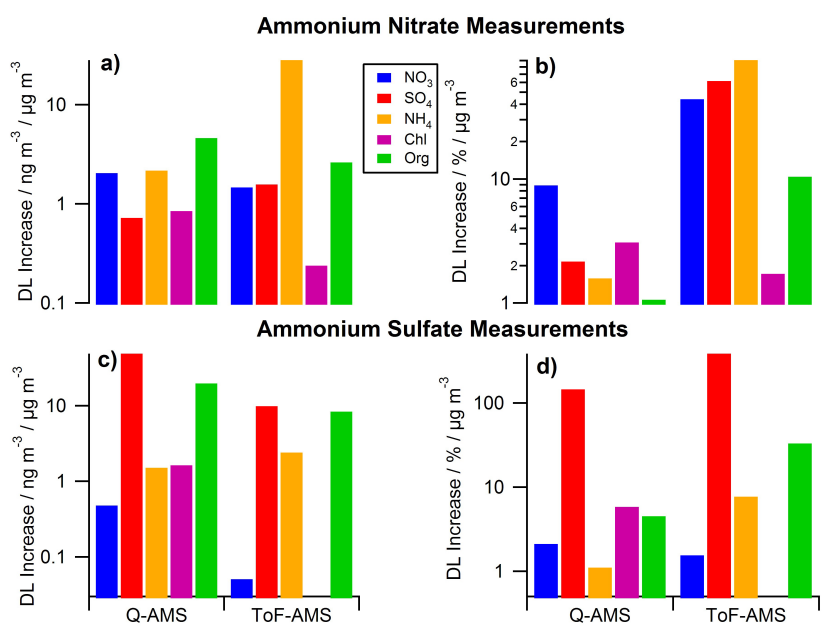

Fig. 3. Influence of increased aerosol mass concentrations on detection limits of the individual species ( $30 \mathrm{~s}$ averaging time). Upper panels: measurement of ammonium nitrate aerosol; lower panels: measurement of ammonium sulfate aerosol. Left panels: absolute increase in $D L$ levels; right panels: relative increase of $D L$. Increases are based on $\mu \mathrm{g} \mathrm{m}^{-3}$ of nitrate or sulfate for all species besides ammonium. For ammonium they are based on $\mu \mathrm{g} \mathrm{m}^{-3}$ of ammonium measured.

$D L$ for each species (panels a and c), the relative increases per $\mu \mathrm{g} / \mathrm{m}^{3}$ aerosol concentration are shown (panels $\mathrm{b}$ and $\mathrm{d}$ ). The values presented in Fig. 3 are generated for each species (color of bars, see legend) by calculating a linear fit to the $D L$ values measured at the individual aerosol concentrations with the intercept forced to the $D L$ value of the filter measurements.

As expected, when measuring ammonium nitrate aerosol the ammonium and nitrate background in the instrument increases, resulting in increased detection limits for these species. The same is true for ammonium and sulfate $D L$ during measurements of ammonium sulfate. However, also the detection limits of species that are not in the aerosol are increased during the aerosol measurements. We call this effect "cross-sensitivity" of $D L$. The cross sensitivity is mainly caused by ions that are generated by the aerosol species (ammonium, nitrate, and sulfate, potentially water), which produce signal in the mass spectra at $\mathrm{m} / \mathrm{z}$ where other species also have fragments. This is the case for example for organics that has fragments at several $\mathrm{m} / \mathrm{z}$ that also contain sulfate or nitrate fragments. Similarly an isotope of a nitrate fragment $\left(\mathrm{NO}_{2}^{+}\right.$at $\left.m / z 48\right)$ contributes to the sulfate $\mathrm{SO}^{+}$signal background at the same $m / z$. Such associations between the aerosol species and chloride and contributions of ammonium and sulfate on nitrate background do not exist. Therefore the cross-sensitivity for these species and the resulting increases in species detection limits are relatively low $\left(\sim 1 \mathrm{ng} \mathrm{m}^{-3}\right.$ and less $D L$ increase per $\mu \mathrm{g} \mathrm{m}^{-3}$ aerosol concentration).
The absolute increase in nitrate $D L$ values during the measurement of ammonium nitrate is in the order of $1-2 \mathrm{ng} \mathrm{m}^{-3}$ per $\mu \mathrm{g} \mathrm{m}^{-3}$ measured nitrate mass concentration for both instruments. A similar value was found for ammonium using the Q-AMS, while a 20 times larger value was found in the case of the ToF-AMS. We assume this is related to water input (incomplete drying of particles) into the instrument during this measurement, causing a background contribution that remains in the instrument for relatively long times (see below). During the measurement of ammonium sulfate the ammonium $D L$ increase again in the order of two $\mathrm{ng} \mathrm{m}^{-3}$ per $\mu \mathrm{g} \mathrm{m}^{-3}$ measured aerosol concentration. A significantly larger change was found for the sulfate $D L$ values that increase by $10-50 \mathrm{ng} \mathrm{m}^{-3}$ per $\mu \mathrm{g} \mathrm{m}^{-3}$ measured sulfate concentration. This indicates that the sulfate molecules generate a relatively persistent background, causing large residual sulfate concentrations while the ammonium and nitrate background is relatively well pumped out of the ionizer chamber.

Increased detection limits of species that are measured at high concentrations do certainly not affect the ability to reliably measure these aerosol components. However, $D L$ values of other species, increased by cross-sensitivity effects can limit the instruments' capabilities to measure these species under certain conditions, where very large concentrations of one species occur together with very small concentrations of the other species. Especially for the ToF-AMS where the relative increases in $D L$, caused by cross-sensitivity effects are much larger than for the Q-AMS (due to the lower absolute $D L$ levels, see Fig. $3 \mathrm{~b}$ and d, but also due to less efficient separation of ions from adjacent $m / z$ in ToF mass spectrometers, compared to quadrupole mass spectrometers) such conditions could occur. For example a $10 \mu \mathrm{g} \mathrm{m}^{-3}$ nitrate or sulfate concentration would increase the ToF-AMS organics $D L$ by a factor of 2 or 4 , respectively. For the Q-AMS limitations due to cross-sensitivity effects are very unlikely. Here it must again be noted that the $D L_{\text {stat }}$ values determined by statistical considerations are only a good estimate of the actual detection limits as long as cross sensitivity (which is not considered in the $D L_{\text {stat }}$ calculation) does not play a role for the detection limit levels.

\subsubsection{Short-term instrument history}

While increased $D L$ levels of species that are measured at elevated concentrations do not affect the capability to determine their concentrations, background concentrations that remain high for a certain time after the aerosol concentrations dropped to lower levels could limit the detection of these aerosol species. In order to determine the self-cleaning time constants of the instrument for the different species, perturbation experiments have been performed where the measurement was suddenly switched from very high aerosol mass concentrations (100-200 $\mu \mathrm{g} \mathrm{m}^{-3}$ ) to filtered air and the background concentrations were monitored as a function of self-cleaning time. 
Table 3. Self-cleaning time constants (time after which the excess detection limit has decreased to $1 / e$ of the detection limit at a high mass concentration of ammonium nitrate, ammonium sulfate, or PSL) of Q-AMS and ToF-AMS.

\begin{tabular}{lcccccccc}
\hline Pertubation Aerosol & \multicolumn{2}{c}{} & \multicolumn{2}{c}{$\begin{array}{c}\text { Self-Cleaning Time Constants/seconds } \\
\text { Nulfate }\end{array}$} & \multicolumn{2}{c}{ Ammonium } & \multicolumn{2}{c}{ Organics } \\
& Q-AMS & ToF-AMS & Q-AMS & ToF-AMS & Q-AMS & ToF-AMS & Q-AMS & ToF-AMS \\
\hline $\mathrm{NH}_{4} \mathrm{NO}_{3}$ & 10 & 80 & - & - & N/A & 120 & - & - \\
$\left(\mathrm{NH}_{4}\right)_{2} \mathrm{SO}_{4}$ & - & - & 60 & N/A & 30 & N/A & - & - \\
$\mathrm{PSL}$ & - & - & - & - & - & - & N/A & 20 \\
\hline
\end{tabular}

Because during the self-cleaning process the background concentrations show a systematic decay on top of the statistical variations, the $D L$ cannot be calculated simply as standard deviation of the measured background values. The temporal evolution of the detection limits was obtained with an iterative approach that uses the standard deviation of the background measurements in a sliding window and assuming that at the end of the measurement $(\sim 1.5 \mathrm{~h}$ after the perturbation) no systematic background decay is observed. The self-cleaning time constants $\tau_{s}$ summarized in Table 3 are the times after which the $D L$ have decayed to $1 / e$ of the value during the measurement of high aerosol concentrations. As a consequence of the indirect calculation of the $D L$ values, the $\tau_{s}$ in Table 3 are subject to relatively large uncertainties. Generally the time constants that describe the decay of the instruments' detection limits are on the order of a few tens of seconds, much shorter than typical changes in ambient aerosol concentrations. Therefore short-term instrument history is typically not a limiting effect for ambient aerosol measurements. However, during measurement of very rapidly changing aerosol concentrations like in aircraft or car-chasing measurements, in exhaust measurements, or in laboratory experiments large and abrupt changes in aerosol concentrations could result in situations where detection limit increases could prevent the reliable detection of low aerosol concentrations for a short time interval.

More information about the dynamics of the instrument's background and its influence on aerosol quantification was extracted using the data of the elevated aerosol concentration measurements and the perturbation experiments. After a particle hits the vaporizer's surface, the non-refractory aerosol components flash-vaporize and a burst of molecules is generated that quickly decays with a time constant of few tens of microseconds (Drewnick et al., 2005). The vast majority of molecules are not ionized and, therefore, not used in the analysis and disperse into the available space. Molecules hitting a surface stick there for a time depending on their sticking properties and the temperature of the surface, before they are re-emitted into the vacuum chamber. Molecules hitting the entrance of the turbo molecular pump are removed from the system. In addition to the vapor generated on the vaporizer less volatile particles can bounce off the vaporizer surface

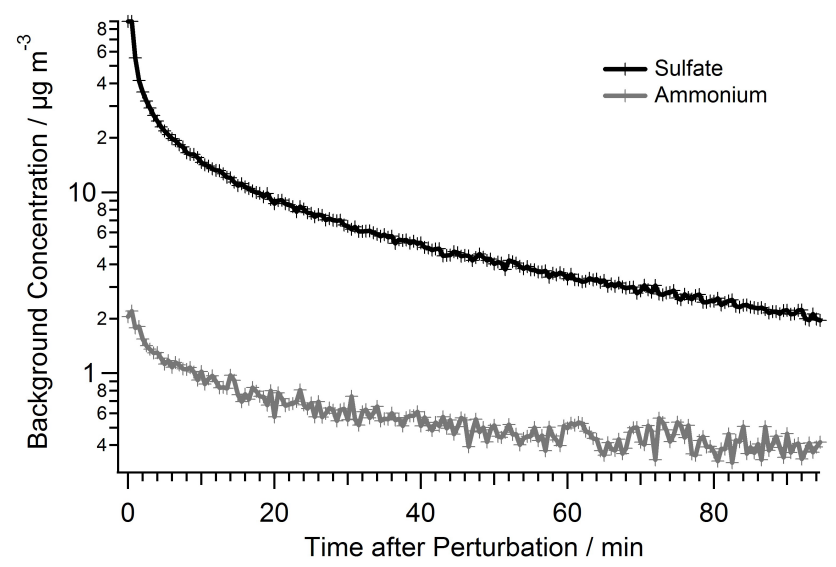

Fig. 4. Decay of Q-AMS sulfate and ammonium signal background after perturbation with $140 \mu \mathrm{g} \mathrm{m}^{-3}$ ammonium sulfate aerosol.

before evaporation (Huffmann et al., 2005). If these particles stick to the colder surfaces of the ionizer chamber they will slowly evaporate and contribute to the effect described above. Very shortly after the particle evaporation, a large fraction of the molecules is still within the ionizer volume. Due to the relatively hot surface temperatures, they are quickly reemitted from the surfaces and the vapor concentration decays quickly. Later, when the molecules stick preferentially on the cooler chamber surfaces the re-emission delay increases and the decay of background concentration slows down.

This dynamics of background concentrations is reflected in the decay of the species' background after perturbation with large aerosol concentrations. Figure 4 shows the decay of the ammonium and sulfate background concentration in the Q-AMS after a perturbation with $140 \mu \mathrm{g} \mathrm{m}^{-3}$ ammonium sulfate aerosol. The log scale clearly shows the gradual increase in self-cleaning time constants over the process of background decay. Similar observations were made for the background decay of the other species after the measurement of high aerosol concentrations with both instrument types. Typically during the first few minutes $(\sim 0.4-3 \mathrm{~min})$ after the perturbation the background decay time constants are on the order of one minute. Later $(\sim 1-10 \mathrm{~min})$ these time constants increase to several minutes (typically $2-5 \mathrm{~min}$ ). During the 
late phase of the instrument self-cleaning (10-70 min after perturbation) process, the time constants are on the order of several tens of minutes (20-120 min).

These results indicate that the self-cleaning time constants decrease as one gets closer to the beginning of the cleaning processes. However, the time range of the aerosol beamto-background measurement alternation (in typical measurement situations $4-5 \mathrm{~s}$ ) is not accessible with this method. At least integral information about this early phase of background decay can be obtained from the ratio of measured aerosol and background mass concentrations and its increase as a function of aerosol mass loading. During measurements of ammonium nitrate aerosol the nitrate background increased by $0.005 \mu \mathrm{g} \mathrm{m}^{-3}$ per $\mu \mathrm{g} \mathrm{m}^{-3}$ nitrate concentration measured. This means that the vapor background concentration in the ionizer decays to an average of $\sim 0.5 \%$ of the vapor concentration of the aerosol measurement during the background measurements (measurement with particle beam blocked, $\sim 4-5 \mathrm{~s}$ ). For ammonium a typical increase in background concentration of $5 \%$ of the measured aerosol concentration is observed, i.e. the vapor concentration decreases to an average of $\sim 5 \%$ of its aerosol measurement value during the background measurement time interval. During the measurements of ammonium sulfate and PSL aerosol very different ratios of aerosol beam to background measurement values were found. In the ToF-AMS the sulfate and organics values decreased to an average of $10-15 \%$ after the switching from one part of the measurement to the other part. In the Q-AMS the sulfate background increased by $85 \%$ of the measured sulfate concentrations and the organics background increased by almost $250 \%$ of the measured organics concentration. This indicates that both, the sulfate and the PSL vapor background decay time constants are in the same order of magnitude as the switching rate between aerosol and background measurements and thus during the time interval of the background measurement a significant decay of the background signal occurs. The consequence of this slow background decay, compared to the aerosol beam/background measurement switching, is that the calculated aerosol concentration (i.e. the difference between the two measurements) is biased low. The reason of the observed differences between the two instruments is likely a lower temperature of the heated surface of the ionizer of the Q-AMS, causing slower cleaning of the ionizer for low vapor pressure species. Typically the ionizer wall temperature is above $\sim 200^{\circ} \mathrm{C}$, where ammonium nitrate flash vaporizes. Therefore no such difference is observed for the ammonium and nitrate data. In order to avoid such under-estimation of species with low vapor pressure, the ionizer temperature must be kept sufficiently high or the particle beam and background measurement intervals must be long enough to allow for the background to decay well before the end of the background measurement interval. Whether these conditions are met can be checked by measuring the aerosol beam-tobackground concentration ratio. If the background increase during a measurement is not larger than $\sim 10 \%$ of the measured aerosol concentration no significant bias due to this effect is expected.

\subsubsection{Long-term instrument contamination}

For species with even lower vapor pressure or high sticking efficiency on the chamber walls the background decay can become very slow, resulting in long-term background increase - i.e. instrument contamination. Such species that can cause increased background concentrations in the instrument over many days or even weeks of operation include water vapor, $\mathrm{NaCl}, \mathrm{KCl}$, iodine-containing species or sticky organic species. While the slow background decay does not affect mass concentration determination, the increased background concentrations cause elevated $D L$ levels for all species that have signal at the same $m / z$ as the contamination signals. Such a long-term contamination with $\mathrm{NaCl}$ has caused the relatively large detection limit of chloride in the ToF-AMS filter measurements, presented above. The typical approach to remove such long-term contaminations is to heat-out the instrument, i.e. pump the instrument for several days with elevated vaporizer temperature.

\subsection{Reduction of AMS detection limits}

Since the AMS detection limits are mainly determined by ion counting statistics limitations the most straight-forward approach to improve AMS $D L$ is to increase the time spent measuring the individual $\mathrm{m} / \mathrm{z}$ signals. This can be done by simply increasing the averaging time $t_{s}$ of the data acquisition. In order to check whether the detection limits of the different species really decrease proportionally to $1 / \operatorname{sqrt}\left(t_{s}\right)$ the filter measurement data were averaged over eight different time intervals $t_{s}$ before calculating the detection limits. The $D L$ were always calculated for the same total time interval to keep the influence of systematic background variations constant. The calculated Q-AMS detection limits are plotted versus $1 / \operatorname{sqrt}\left(t_{s}\right)$ in Fig. 5a. Results show that a linear relationship is found for all species between the detection limit calculated for different averaging times and the inverse square root of the averaging time, indicating that the statistical contribution to the $D L$ can be reduced by increasing the averaging time as expected. By extending the averaging time to infinitely long intervals purely statistical noise should vanish. Linear fits to the data presented in Fig. 5a were calculated. Their intercept $\left(1 / \operatorname{sqrt}\left(t_{s}\right)=0 \rightarrow t_{s}=\infty\right)$ gives the residual detection limit under these measurement conditions. While for nitrate, sulfate, ammonium and chloride the intercept of these fits is not significantly different from zero a residual detection limit of $\sim 50 \mathrm{ng} \mathrm{m}^{-3}$ is found for organics for infinitely long averaging times. Also for the ToF-AMS (Fig. 5b) the nitrate and sulfate detection limits do not show a significant residual value for very long averaging times. Here for ammonium and organics residual $D L$ values were found, 

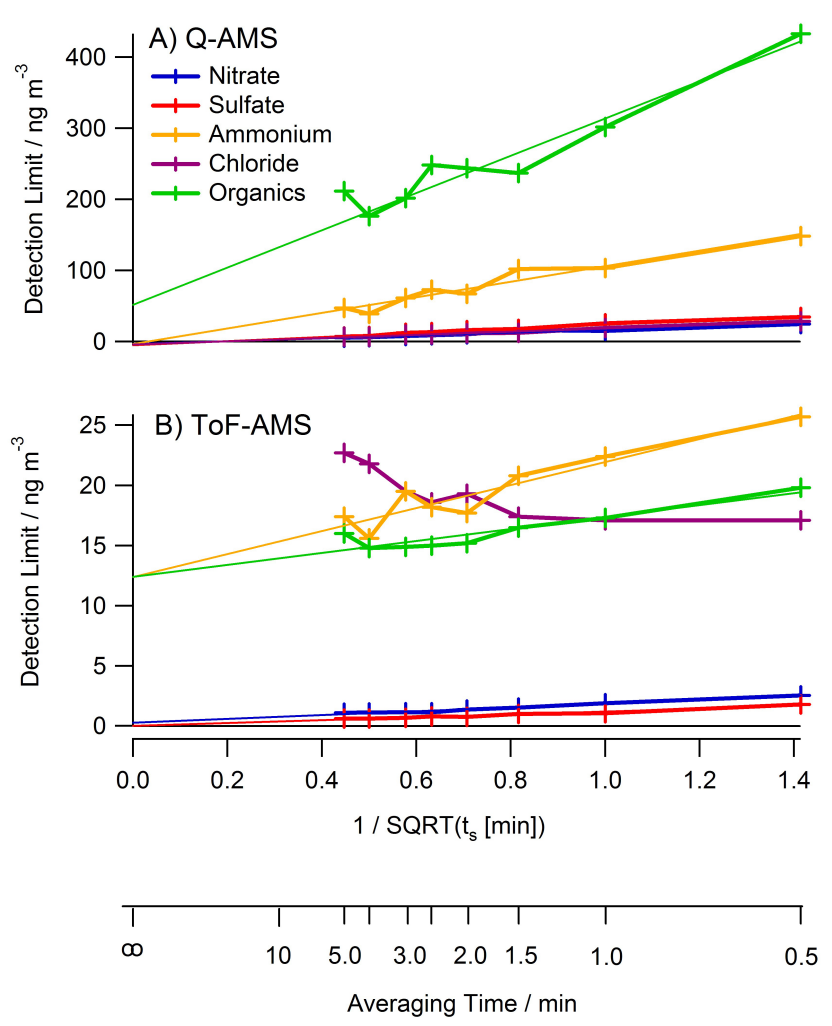

Fig. 5. AMS detection limits for various averaging times plotted versus the inverse square root of the averaging time for Q-AMS (A) and ToF-AMS (B).

both in the order of $15-20 \mathrm{ng} \mathrm{m}^{-3}$. For chloride the calculated data points showed a large variation with no uniform trend and no meaningful fit was possible.

Apparently the measured detection limits of most species of the two AMS instrument types are dominated by counting statistics and other statistical noise that can efficiently be reduced by increasing the measurement time. For most species this allows to reduce the detection limits to very low values until other effects dominate the detection limits. For organics and ToF-AMS ammonium a residual detection limit in the order of $15-20 \mathrm{ng} \mathrm{m}^{-3}$ (ToF-AMS) and $50 \mathrm{ng} \mathrm{m}^{-3}$ (Q-AMS) is found even for very long averaging times. We assume that these residual $D L$ are caused by cross-contamination of the species by water vapor (ammonium and organics) and $\mathrm{CO}_{2}$ (organics), which will not disappear even after very long averaging.

While simply increasing the averaging time efficiently reduces the species' detection limits it is always a trade-off with reduced temporal resolution of the measurement. In cases where time resolution should be kept high the detection limits can also be improved within certain limits by increasing only the measurement time of those $\mathrm{m} / \mathrm{z}$ that are essential for calculation of the species concentrations. In the Q-AMS this can be done by selective ion monitoring, i.e. measuring only the signal at a few selected $\mathrm{m} / \mathrm{z}$ that are needed to calculate the species mass concentrations (Crosier et al., 2007) or by scanning only a reduced mass range (e.g. up to $m / z 200$ instead of 300). In the ToF-AMS the ion duty cycle for the small $\mathrm{m} / \mathrm{z}$ (where the fragments of the inorganic species are located) can be increased by pulsing the mass spectrometer with higher frequency - reducing the largest $\mathrm{m} / \mathrm{z}$ in the mass spectra. Both methods result in slightly improved detection limits without reducing the time resolution of the measurements. However, both methods are a trade-off with reduced mass spectral information and increased mass concentration uncertainty due to the use of correction factors for $\mathrm{m} / \mathrm{z}$ not measured.

Especially in measurements at very low mass concentrations often the chopper ratio - i.e. the fraction of time measuring the particle beam versus measuring the background is changed in favor of the aerosol measurement to increase particle counting statistics. While this increase in aerosol measurement time increases the number of particles measured it deteriorates the absolute mass concentration detection limits because the decrease of background measurement time over-compensates the improved ion counting statistics of the longer aerosol measurement time interval. Under such conditions Eq. (4) is not appropriate to determine the detection limit of the measurement since different measurement times for the particle beam and the instrument background result in different error curves for both parts of the measurement.

As shown in Table 1 the organics $D L$ are significantly higher than those of the other species due to the large number of mass fragments contributing ion signals and also noise to the total organics signal (Fig. 2). In order to investigate whether it is possible to reduce the organics $D L$ by using only a selection of mass fragments and correcting for the omitted fraction, the following tests have been performed with the ToF-AMS and Q-AMS filter data.

The organics $D L$ was calculated from the filter test data presented above using different selections of mass fragments. To determine the selection of these fragments, the $m / z$ were first sorted in order of decreasing organic signal and decreasing organic signal-to-noise (standard deviation of background signal). Then increasing numbers of mass fragments were used to calculate the $D L$, starting with only the mass fragment with the most intense signal, followed by the first two most intense signals and so on, until all organic mass fragments were used. The same procedure was applied on the sorted signal-to-noise ratios and the unsorted $\mathrm{m} / \mathrm{z}$ (using the first organic-related peak in the mass spectrum, using the first two peaks and so on). The peak intensity and signal-tonoise information were taken from an average mass spectrum of suburban aerosol from a field campaign performed with the ToF-AMS. For individual applications of this method to improve organics $D L$ the average mass spectrum of the actual measurement has to be used to get information on how the ion signals should be sorted.

For each of the ion peak selections the $D L$ was calculated from the filter test data. These $D L$ were then corrected for 

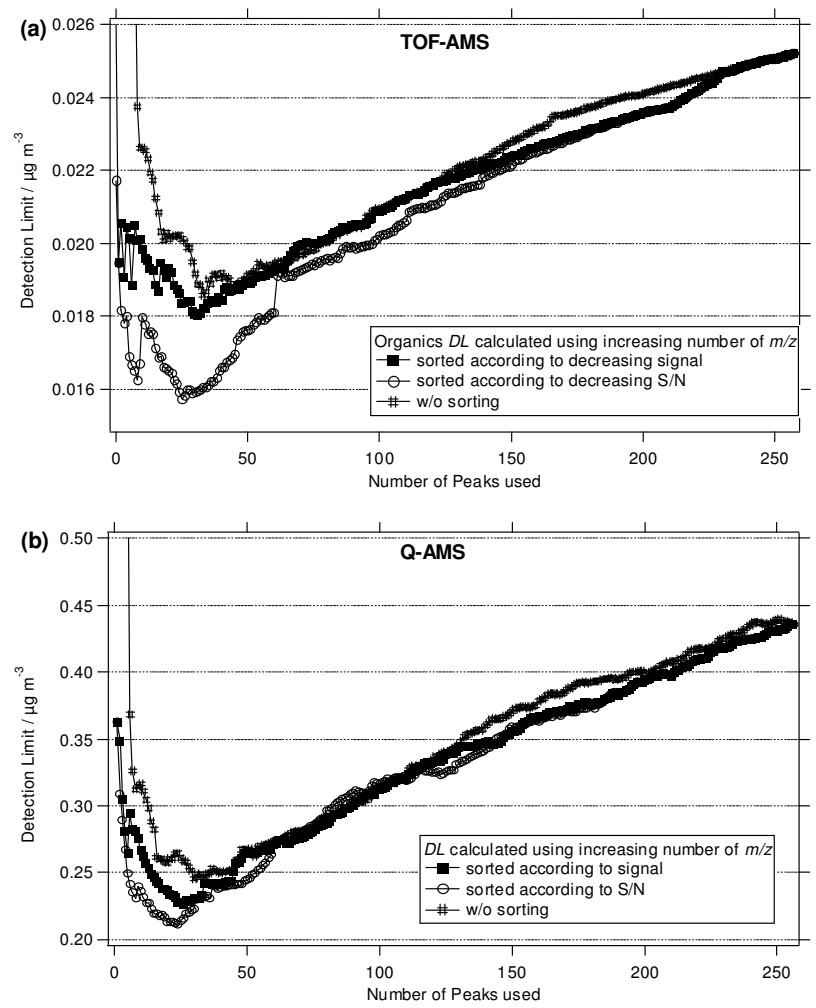

Fig. 6. (a) ToF-AMS and (b) Q-AMS $D L$ from filter measurements (30 s averaging time), calculated using an increased number of selected $\mathrm{m} / \mathrm{z}$ after different ways of sorting the signals. The lowest $D L$ is achieved for the first 24-25 peaks with the largest $S / N$ ratio. The jumps in the $D L$ values are likely caused by the different contributions to overall noise and overall signal by the individual $\mathrm{m} / \mathrm{z}$.

the omitted ion signals to obtain total organics concentration. The summary of the results of all these calculations are presented in Fig. 6. It can be seen that different $D L$ values were obtained for different selections of mass fragments. The largest reduction in $D L$ was found when the mass fragments were sorted in order of decreasing signal-to-noise ratios and if the mass fragments with the 25 and the 24 largest signalto-noise ratios were used for the $D L$ calculation of ToF-AMS and Q-AMS, respectively. This minimum achievable $D L$ for organics is $16 \mathrm{ng} \mathrm{m}^{-3}$ for the ToF-AMS compared to a $D L$ of $25 \mathrm{ng} \mathrm{m}^{-3}$ when all ion signals are used and $210 \mathrm{ng} \mathrm{m}^{-3}$ compared to $440 \mathrm{ng} \mathrm{m}^{-3}$ for the Q-AMS. Thus a reduction of organics $D L$ by approximately a factor of two is possible for both instruments, using only a selection of ion signals to calculate total organics. However, it must be noted that while the organics detection limits (i.e. the precision of the measurement) are improved using this method the uncertainties of the organics mass concentration are increased (i.e. the accuracy is reduced) due to the uncertainty of the correction for the omitted mass fragments.

\section{Summary}

For the first time, a systematic characterization of the mass concentration detection limits of the analytical systems of the c-ToF-AMS and the Q-AMS has been performed for various measurement conditions. For this purpose a new method to continuously derive AMS detection limits during regular measurements was developed, based on the instrument background signal only. Measurements have shown that this method is in good agreement with the standard method used in the AMS community, where filtered air is measured for a certain time interval. In addition to the investigation of detection limits a thorough discussion on instrument background effects on aerosol quantification is provided.

Minimum detection limits for the individual species have been determined by measurements of filtered air. It was found that the ToF-AMS detection limits were lower by a factor of approximately 10 than the Q-AMS $D L$, mainly due to the larger ion duty cycle of the ToF-AMS analysis. For species with no large background contamination and a small number of fragments (nitrate, sulfate, chloride) the ToFAMS detection limits are in the order of $3 \mathrm{ng} \mathrm{m}^{-3}$, the QAMS $D L$ are approximately $30 \mathrm{ng} \mathrm{m}^{-3}$. The ammonium $D L$ is increased by large background contributions from water vapor and air to $30 \mathrm{ng} \mathrm{m}^{-3}$ (ToF-AMS) and $140 \mathrm{ng} \mathrm{m}^{-3}$ (QAMS). The large number of fragments contributing to the organics signal causes large detection limits for this species on the order of $25 \mathrm{ng} \mathrm{m}^{-3}$ for the ToF-AMS and of $440 \mathrm{ng} \mathrm{m}^{-3}$ for the Q-AMS.

Detection limits derived from ion counting statistics considerations have been found to provide a good estimate of the actual $D L$ only for situations where cross-contamination effects do not contribute significantly to the background variation.

Under real measurement conditions the actual detection limits can be increased compared to the values given above. Such $D L$ increases can be caused by cross contamination of the background of one species during the measurement of large concentration of another species that generates fragments at the same $m / z$. Short term instrument history - i.e. recently measured high concentrations of species - can affect the measurement of low concentrations during a short period (few minutes) after an abrupt change of concentrations. The most common effect causing increased detection limits is probably instrument contamination by low vapor pressure or sticky species like $\mathrm{NaCl}, \mathrm{KCl}$, iodine-containing species, $\mathrm{H}_{2} \mathrm{O}$ or some organic compounds that cause a longterm background increase at certain $\mathrm{m} / \mathrm{z}$.

The same processes causing self-cleaning of the ionizer after measurement of high aerosol concentrations - vapor diffusion delayed by wall adsorption/desorption - control the ionizer background decay during the switching between aerosol and background measurements in regular AMS operation. For sticky molecules and sufficiently cold ionizer walls background decay time constants can be in the order 
of the switching rate, resulting in measured aerosol concentrations that are biased low. In order to avoid this measurement artifact the switching rate should be kept sufficiently low or the ionizer should be sufficiently hot to avoid measured background concentrations above $\sim 10 \%$ of the actual aerosol concentrations.

The most straight-forward approach to improve AMS detection limits is to increase the averaging times $t_{s}$ of aerosol measurements since statistical noise scales with $1 / \operatorname{sqrt}\left(\mathrm{t}_{s}\right)$. $D L$ values calculated for various averaging times showed a good agreement with this expected dependency. Therefore for most species efficient reduction of detection limits to very low values can be achieved by this approach. Species that are subject to significant cross-contamination (e.g. by water vapor or $\mathrm{CO}_{2}$ ) show a residual detection limit even for very long averaging times that are in the order of few tens of $\mathrm{ng} / \mathrm{m}^{3}$. While this approach reduces the temporal resolution of the measurement the time spent measuring individual $\mathrm{m} / \mathrm{z}$ can also be increased by selective ion monitoring (QAMS) or faster pulsing of the ToF-MS (ToF-AMS) without reducing the measurement time resolution - in this case at the expense of mass spectrometric information. In the case of organics, the detection limits can be reduced by a factor of two by using only the $\sim 25 \mathrm{~m} / \mathrm{z}$ with the largest signal-tonoise ratio for organics concentration calculation.

Acknowledgements. This research was supported by the EU Research Fund for Coal and Steel under contract number RFS-CR04049. Silke Hings acknowledges support from the International Max Planck Research School for Atmospheric Chemistry and Physics and the Johannes Gutenberg University in Mainz. We acknowledge Sören Zorn for helpful discussions.

Edited by: Pinhua Xie

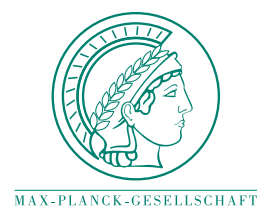

This Open Access Publication is financed by the Max Planck Society.

\section{References}

Alfarra, M. R., Coe, H., Allan, J. D., Bower, K. N., Boudries, H., Canagaratna, M. R., Jimenez, J. L., Jayne, J. T., Garforth, A., Li, S. M., and Worsnop, D. R.: Characterization of Urban and Regional Organic Aerosols In the Lower Fraser Valley Using Two Aerodyne Aerosol Mass Spectrometers, Atmos. Environ., 38, 5745-5758, 2004.

Allan, J. D., Coe, H., Bower, K. N., Williams, P. I., Gallagher, M. W., Alfarra, M. R., Jimenez, J. L., Worsnop, D. R., Jayne, J. T., Canagaratna, M. R., Nemitz, E., and McDonald, A. G.: Quantitative Sampling Using an Aerodyne Aerosol Mass Spectrometer. Part 2: Measurements of Fine Particulate Chemical Composition in Two UK Cities, J. Geophys. Res.-Atmos., 108(D3), 4091, doi:10.1029/2002JD002359, 2003a.
Allan, J. D., Jimenez, J. L., Coe, H., Bower, K. N., Williams, P. I., and Worsnop, D. R.: Quantitative Sampling Using an Aerodyne Aerosol Mass Spectrometer. Part 1: Techniques of Data Interpretation and Error Analysis, J. Geophys. Res.-Atmos., 108(D3), 4090, doi:10.1029/2002JD002358, 2003b.

Allan, J. D., Coe, H., Bower, K. N., Alfarra, M. R., Delia, A. E., Jimenez, J. L., Middlebrook, A. M., Drewnick, F., Onasch, T. B., Canagaratna, M. R., Jayne, J. T., and Worsnop, D. R.: Technical note: Extraction of chemically resolved mass spectra from Aerodyne aerosol mass spectrometer data, J. Aerosol Sci., 35, 909-922, 2004.

Bahreini, R., Jimenez, J. L., Wang, J., Flagan, R. C., Seinfeld, J. H., Jayne, J. T., and Worsnop, D. R.: Aircraft-based Aerosol Size and Composition Measurements during ACE-Asia using an Aerodyne Aerosol Mass Spectrometer, J. Geophys. Res.-Atmos., 108(D23), 8645, doi:10.1029/2002JD003226, 2003.

Canagaratna, M. R., Jayne, J. T., Jimenez, J. L., Allan, J. D., Alfarra, M. R., Zhang, Q., Onasch, T. B., Drewnick, F., Coe, H., Middlebrook, A., Delia, A., Williams, L. R., Trimborn, A. M., Northway, M. J., DeCarlo, P. F., Kolb, C. E., Davidovits, P., and Worsnop, D. R.: Chemical and Microphysical Characterization of Ambient Aerosols with the Aerodyne Aerosol Mass Spectrometer, Mass Spectrom. Rev. 26, 185-222, 2007.

Crosier, J., Jimenez, J. L., Allan, J. D., Bower, K. N., Williams, P. I., Alfarra, M. R., Canagaratna, M. R., Jayne, J. T., Worsnop, D. R., and Coe, H.: Technical Note: Description and use of the new Jump Mass Spectrum mode of operation for the Aerodyne Quadrupole Aerosol Mass Spectrometer (Q-AMS), Aerosol Sci. Tech., 41, 829-839, 2007.

DeCarlo, P. F., Kimmel, J. R., Trimborn, A., Northway, M. J., Jayne, J. T., Aiken, A. C., Gonin, M., Fuhrer, K., Horvath, T., Docherty, K. S., Worsnop, D. R., and Jimenez, J. L.: Field-Deployable, High-Resolution, Time-of-Flight Aerosol Mass Spectrometer, Anal. Chem., 78, 8281-8289, 2006.

Drewnick, F., Hings, S. S., DeCarlo, P. F., Jayne, J. T., Gonin, M., Fuhrer, K., Weimer, S., Jimenez, J. L., Demerjian, K. L., Borrmann, S., and Worsnop, D. R.: A New Time-of-Flight Aerosol Mass Spectrometer (ToF-AMS) - Instrument Description and First Field Deployment, Aerosol Sci. Tech., 39, 637-658, 2005.

Hings, S. S., Walter, S., Schneider, J., Borrmann, S., and Drewnick, F.: Comparison of a Quadrupole and a Time-of-Flight Aerosol Mass Spectrometer during the Feldberg Aerosol Characterization Experiment 2004, Aerosol Sci. Tech., 41, 679-691, 2007.

Hogrefe, O., Drewnick, F., Lala, G. G., Schwab, J. J., and Demerjian, K. L.: Development, Operation and Applications of an Aerosol Generation, Calibration and Research Facility, Aerosol Sci. Tech., 38(S1), 196-214, 2004.

Huffmann, J. A., Jayne J. T., Drewnick, F., Aiken, A. C., Onasch, T., Worsnop, D. R., and Jimenez, J. L.: Design, Modeling, Optimization, and Experimental Tests of a Particle Beam Width Probe for the Aerodyne Aerosol Mass Spectrometer, Aerosol Sci. Tech., 39, 1143-1163, 2005.

Jayne, J. T., Leard, D. C., Zhang, X., Davidovits, P., Smith, K. A., Kolb, C. E., and Worsnop, D. R.: Development of an Aerosol Mass Spectrometer for Size and Composition Analysis of Submicron Particles, Aerosol Sci. Tech., 33, 49-70, 2000.

Jimenez, J. L., Jayne, J. T., Shi, Q., Kolb, C. E., Worsnop, D. R., Yourshaw, I., Seinfeld, J. H., Flagan, R. C., Zhang, X., Smith, K. A., Morris, J. W., and Davidovits, P.: Ambient Aerosol Sam- 
pling Using the Aerodyne Aerosol Mass Spectrometer, J. Geophys. Res.-Atmos., 108(D7), 8425, doi:10.1029/2001JD001213, 2003.

Kellner, R., Mermet, J.-M., Otto, M., Valcarcel, M., and Widmer, H. M. (Eds.): Analytical Chemistry - A Modern Approach to Analytical Science, Second Edition, WILEY-VCH Verlag GmbH \& Co. KgaA, Weinheim, Germany, 2004.

Salcedo, D., Onasch, T. B., Dzepina, K., Canagaratna, M. R., Zhang, Q., Huffman, J. A., DeCarlo, P. F., Jayne, J. T., Mortimer, P., Worsnop, D. R., Kolb, C. E., Johnson, K. S., Zuberi, B., Marr, L. C., Volkamer, R., Molina, L. T., Molina, M. J., Cardenas, B., Bernabé, R. M., Márquez, C., Gaffney, J. S., Marley, N. A., Laskin, A., Shutthanandan, V., Xie, Y., Brune, W., Lesher, R., Shirley, T., and Jimenez, J. L.: Characterization of ambient aerosols in Mexico City during the MCMA-2003 campaign with Aerosol Mass Spectrometry: results from the CENICA Supersite, Atmos. Chem. Phys., 6, 925-946, 2006, http://www.atmos-chem-phys.net/6/925/2006/.

Steiner, W. E., Clowers, B. H., Fuhrer, K., Gonin, M., Matz, L. M., Siems, W. F., Schultz, A. J., and Hill Jr., H. H.: Electrospray ionization with ambient pressure ion mobility separation and mass analysis by orthogonal time-of-flight mass spectrometry, Rapid Commun. Mass Sp., 15, 2221-2226, 2001.
Suess, D. T. and Prather, K. A.: Mass Spectrometry of Aerosols, Chem. Rev., 99, 3007-3035, 1999.

Takegawa, N., Miyazaki, Y., Kondo, Y., Komazaki, Y., Miyakawa, T., Jimenez, J. L., Jayne, J. T., Worsnop, D. R., Allan, J., and Weber, R. J.: Characterization of an Aerodyne Aerosol Mass Spectrometer (AMS): Intercomparison with other aerosol instruments, Aerosol Sci. Tech., 39, 760-770, 2005.

Zhang, Q., Canagaratna, M. R., Jayne, J. T., Worsnop, D. R., and Jimenez, J. L.: Time and Size-Resolved Chemical Composition of Submicron Particles in Pittsburgh - Implications for Aerosol Sources and Processes, J. Geophys. Res.-Atmos., 110(D07), 09, doi:10.1029/2004JD004649, 2005.

Zhang, X., Smith, K. A., Worsnop, D. R., Jimenez, J. L., Jayne, J. T., and Kolb, C. E.: A Numerical Characterization of Particle Beam Collimation by an Aerodynamic Lens-Nozzle System: Part I. An Individual Lens or Nozzle, Aerosol Sci. Tech., 36, 617-631, 2002.

Zhang, X., Smith, K. A., Worsnop, D. R., Jimenez, J. L., Jayne, J. T., Kolb, C. E., Morris, J., and Davidovits, P.: Characterization of Particle Beam Collimation: Part II. Integrated Aerodynamic Lens-Nozzle System, Aerosol Sci. Tech., 38(6), 619-638, 2004. 